\title{
Global scientific collaboration in COPD research
}

This article was published in the following Dove Press journal:

International Journal of COPD

6 January 2017

Number of times this article has been viewed

\section{Yanbing Su' \\ Chao Long ${ }^{2}$ \\ Qi Yu' \\ Juan Zhang' \\ Daisy $\mathrm{Wu}^{3}$ \\ Zhiguang Duan'}

'School of Management, Shanxi Medical University, Taiyuan, People's Republic of China; ${ }^{2}$ School of Medicine, Stanford University, Palo Alto, CA, ${ }^{3}$ Department of Molecular and Cellular Physiology, University of Cincinnati College of Medicine, Cincinnati, OH, USA

Correspondence: Zhiguang Duan School of Management, Shanxi Medical University, Taiyuan 03000I, People's Republic of China

Email dzg528@sxmu.edu.cn
Purpose: This study aimed to investigate the multiple collaboration types, quantitatively evaluate the publication trends and review the performance of institutions or countries (regions) across the world in COPD research.

Materials and methods: Scientometric methods and social network analysis were used to survey the development of publication trends and understand current collaboration in the field of COPD research based on the Web of Science publications during the past 18 years.

Results: The number of publications developed through different collaboration types has increased. Growth trends indicate that the percentage of papers authored through multinational and domestic multi-institutional collaboration (DMIC) have also increased. However, the percentage of intra-institutional collaboration and single-authored (SA) studies has reduced. The papers that produced the highest academic impact result from international collaboration. The second highest academic impact papers are produced by DMIC. Out of the three, the papers that are produced by SA studies have the least amount of impact upon the scientific community. A handful of internationally renowned institutions not only take the leading role in the development of the research within their country (region) but also play a crucial role in international research collaboration in COPD. Both the amount of papers produced and the amount of cooperation that occurs in each study are disproportionally distributed between high-income countries (regions) and low-income countries (regions). Growing attention has been generated toward research on COPD from more and more different academic domains.

Conclusion: Despite the rapid development in COPD research, collaboration in the field of COPD research still has room to grow, especially between different institutions or countries (regions), which would promote the progress of global COPD research.

Keywords: research collaboration, social network analysis, COPD, citation frequency

\section{Introduction}

COPD is a common preventable and treatable respiratory disease that is characterized by persistent airflow limitation and is a major cause of significant morbidity and mortality throughout the world. As reported by the World Health Organization (WHO) in 2012, more than three million people died of COPD, which was equal to $6 \%$ of all deaths globally that year. A more recent study predicts it to be the third leading cause of death by $2030 .^{1}$

Numerous researchers devoted themselves to gaining an even deeper understanding of the etiology, ${ }^{2,3}$ diagnosis, ${ }^{4-7}$ therapy, ${ }^{8-10}$ and prevention and control ${ }^{11-13}$ in COPD research. However, there still exists a lack of knowledge about scientific collaboration occurring within the field of COPD. Our goal has been to characterize the multiple collaboration behaviors seen in COPD research at the institution and country (region) levels, because the institution and country (region) collaboration can reveal the collaboration 
at the meso and macro levels, respectively. ${ }^{14}$ More precisely, our major aim was to answer the following research questions:

1. What is the cooperative situation and the trends of collaboration between authors within COPD research publications?

2. Does international or domestic multi-institutional collaboration (DMIC) result in higher amounts of citations in COPD?

3. Which institution or country (region) produces the highest academic impact upon global COPD research and which institution or country (region) is at the core of the institutional or international collaboration network?

4. Has an increasing attention been paid to the research on COPD from more and more different academic fields?

We believe that the results, discussion and conclusion in this paper answer the research questions stated above.

\section{Materials and methods Materials}

This study was based on the analysis of article-level data from the online version of the Web of Science database. COPDrelated articles from Web of Science were suitable for the present study. Data in this study were acquired on March 2, 2016, using the following search strategy: subject = COPD OR chronic obstructive pulmonary disease OR chronic obstructive pulmonary diseases OR chronic obstructive lung disease OR chronic obstructive lung diseases AND publication year $=1900-2015$. Only document types of articles and reviews were included. The query yielded 36,727 records from 1956 to 2015, and each of these results included author names, affiliations, titles, sources, abstracts, total citations (TC), keywords, cited references and study field. Because of a large proportion of the older papers, which were published before 1998, were missing information about their affiliations, so we selected the data from articles that were published between 1998 and 2015. In addition, the articles in which author names were marked as anonymous were removed. In our final dataset, we obtained 31,733 bibliographies. In this study, TC and average citation per paper (ACPP) were used to access the academic impact of institutions or countries (regions), while the percentage of distinguished papers and ACPP were used to compare the academic impact of different collaboration types.

\section{Analysis methods}

Related methods

Social network analysis

Social networks are developed through the social interactions of entities, such as institutions and countries (regions), which work together for a common purpose. Since this information is online and public, researchers are able to use this information to come up with discernible patterns of relationships among them. ${ }^{15}$ Social network analysis provides the methodology to analyze collaboration produced by the relationships of different entities and determine the implications of those relationships.

\section{Related definition}

\section{Distinguished paper}

A distinguished paper in this study is defined as a paper that has been cited more frequently than the average citations per document in its publication year.

\section{Degree centrality}

Degree centrality, based on the idea of social capital, refers to the number of neighbors to a node in the network. According to this measure of centrality, the most important nodes are the ones that have the most ties to other nodes in the network.

\section{Betweenness centrality}

Betweenness centrality is an indicator of a node's centrality in a network. It is calculated by determining how many other actors a single network actor is connected to. Nodes with high betweenness centrality may have the power to control the information that passes between other nodes.

\section{Closeness centrality}

Closeness centrality measures the mean distance from a vertex to other vertices. Based on the indicator, vertices with high closeness centrality have better access to information at other vertices or have a more direct influence on other vertices.

\section{Related indicators}

\section{Cooperation indicators}

1. Multinational collaboration (MNC): the total number of publications produced through international collaboration.

2. DMIC: the number of publications resulting from collaboration among solely domestic institutions.

3. Intra-institutional collaboration (IIC): the number of publications produced through IIC.

4. Single authored (SA): the number of publications produced by a single author.

\section{Institutions' and countries' (regions') academic} impact indicators

1. Total publication (TP): the total number of publications produced by one institution or country (region). 
2. TC: the total number of citations each one institution or country (region) receives on all of their publications.

3. ACPP: TC/TP.

4. Multinational collaboration rate (MNCR): MNC/TP.

5. Domestic multi-institutional collaboration rate (DMICR): $\mathrm{DMIC} / \mathrm{TP}$.

\section{Results \\ Changes in the collaboration scale of research paper}

Figure 1 plots the average number of authors, institutions or countries (regions) per paper between 1988 and 2015. The average number of authors and institutions per paper shows a rapidly increasing trend from 4.71 to 6.84 authors per year and from 1.75 to 3.14 institutions per paper, whereas the average number of countries per paper only increased from 1.13 in 1998 to 1.45 in 2015. As a whole, the rates of collaboration between authors, institutions and countries (regions) are $94 \%, 64 \%$ and $21 \%$, respectively. More than half of the papers have been produced by a collaboration on average of approximately six authors and two to three institutions.

\section{Collaboration trend analysis of research papers}

There has been a substantial increase in the total number of papers in COPD research from 1998 to 2015, as depicted in Figure 2. Figure 2 shows the distribution of publications per year. During the past 18 years, the number of published papers related to COPD has been growing at a constant rate, particularly after 2004. In general, the number of published papers since 1998 has increased more than fourfold, from 603 in 1998 to 3,453 in 2015.

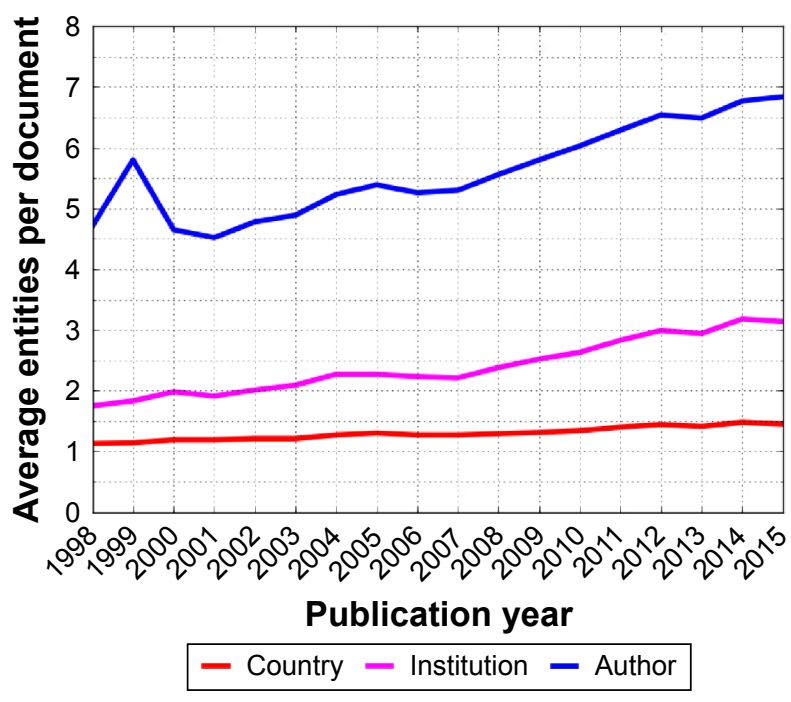

Figure I Average number of different entities per paper, 1998-20I5.

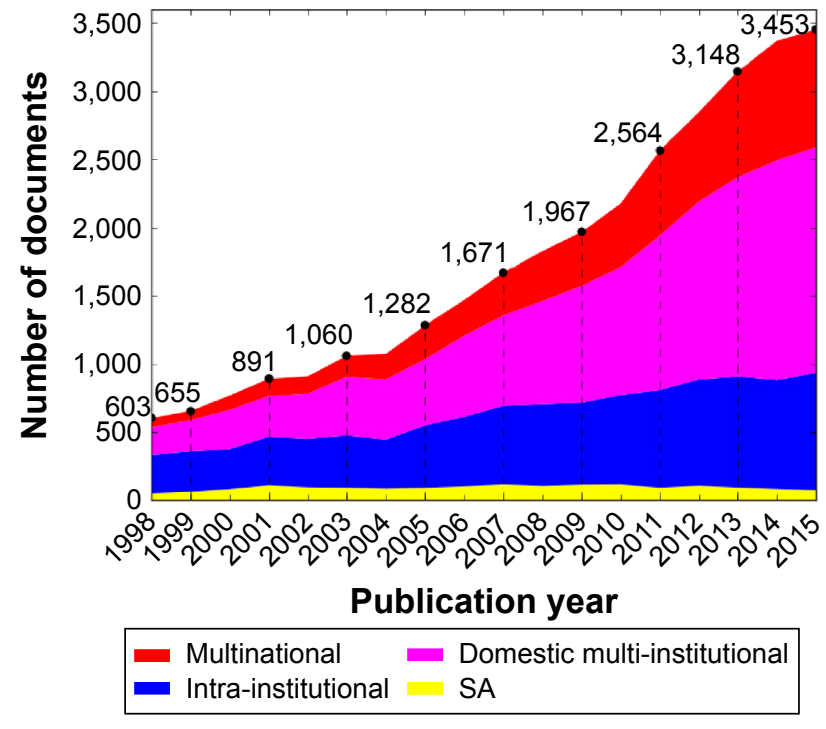

Figure 2 The number of documents in different collaboration types in COPD publications, 1998-2015.

Abbreviation: SA, single authored.

In order to figure out the characteristics of research collaboration in COPD, we analyzed the number of different research collaboration types, including MNC, DMIC, IIC and no collaboration. A total of 31,733 articles were classified according to the types of research collaboration that occurred. We tabulated the number of articles in each type. As a whole, the highest percentage of SCI journal articles that were published in COPD was produced by DMIC (occupying $43 \%$ ). The next highest percentage of papers were produced through IIC accounted for $31 \%(9,704)$. The MNC occupies a relatively small percentage of the papers at $21 \%(6,688)$. The least percentage of papers was produced by no collaboration at only $5 \%(1,667)$. Figure 2 shows the year-wise distribution of different collaboration types' publications. The number of MNC papers, DMIC papers and IIC papers increased rapidly from 1998 to 2015, especially DMIC papers have increased more than sevenfold, from 204 in 1998 to 1,654 in 2015, while no collaboration papers tend to be gentle.

Figure 3 shows the percentage of papers that were studied in each of the different collaboration types described above and their changes over time. The percentages of IIC papers and SA papers have decreased by $22 \%$ and $6 \%$ from 1998 to 2015, respectively. However, both the percentages of DMIC papers and international collaboration papers have increased throughout the years, from $34 \%$ and $11 \%$ in 1998 to $48 \%$ and $25 \%$ in 2015 , respectively. Because of this, we find that DMIC is gradually becoming the major type of cooperation between entities involved on a scientific paper in the field of COPD. Contrary to DMIC, the share of IIC has continuously decreased throughout this time period. By the year 2003, 


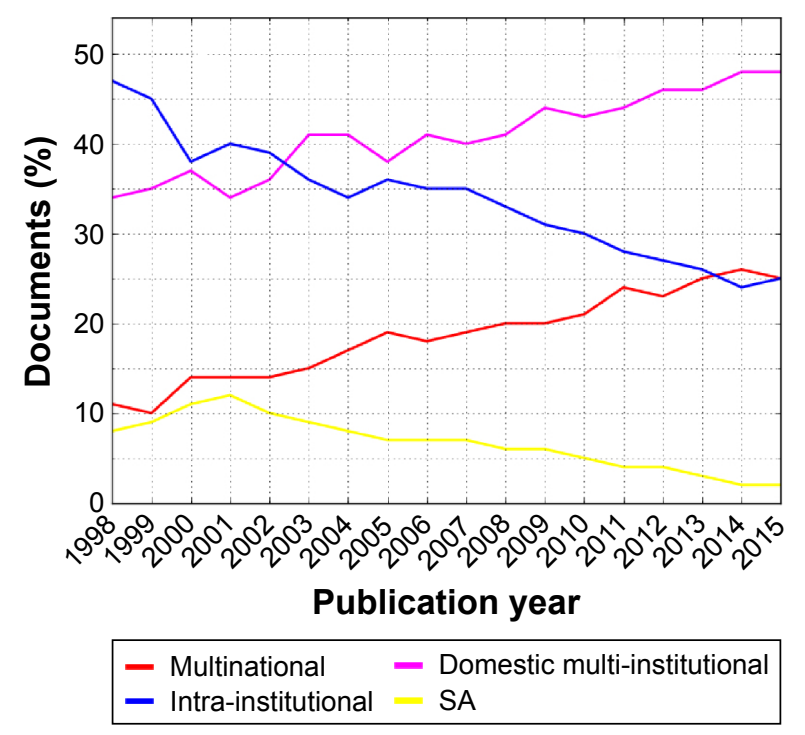

Figure 3 Percentage of different collaboration types in COPD publications, 1998-2015.

Abbreviation: SA, single authored.

the percentage of papers produced through IIC was less than that of DMIC and equal to that produced through international collaboration in 2015.

\section{Collaboration citation impact analysis} Trend of percentage of distinguished paper analysis We calculated the annual percentage of distinguished papers produced in each of different collaboration types. The results in Figure 4 show that the annual percentage of distinguished papers produced through collaboration and no

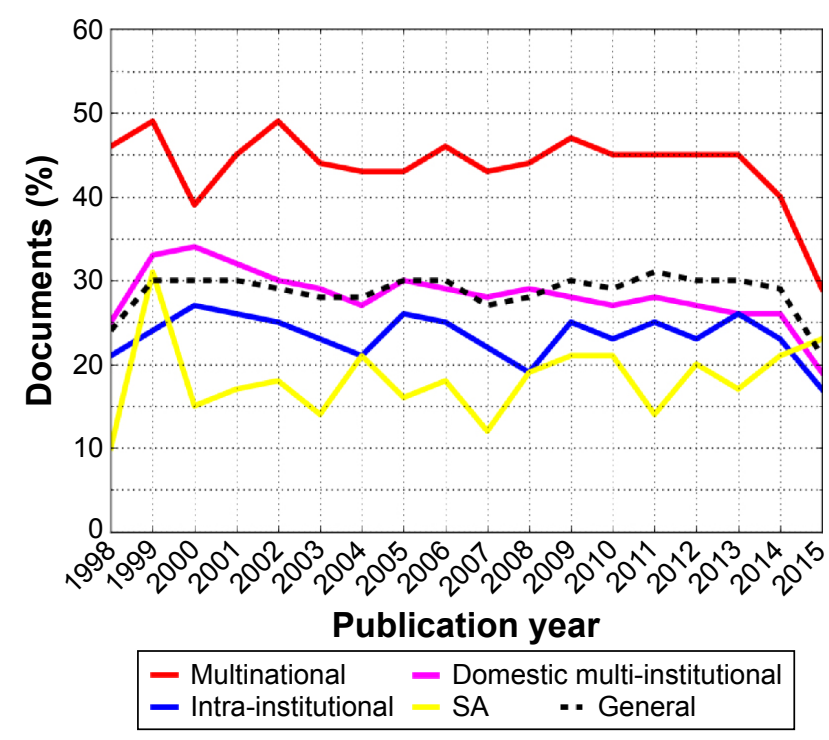

Figure 4 Percentage of distinguished papers in different collaboration types in COPD publications, 1998-2015.

Abbreviation: SA, single authored. collaboration fluctuates during the period 1998-2015. The highest percentage of the distinguished papers was produced by international collaboration, followed by DMIC. Compared to those three different collaboration types, the SA paper had the lowest percentage of the distinguished papers. In comparing the percentages of the different types of collaboration in distinguished papers annually, we found that the percentage of distinguished papers produced through $\mathrm{MNC}$ was higher than the percentage of distinguished papers produced annually, whereas both the percentages of distinguished papers through IIC and SA were lower. The percentage of distinguished papers produced through DMIC was higher than that of the annual percentage from 1998 to 2003, but fell to lower than the annual percentage after 2009.

\section{Trend of average citation per document analysis}

Figure 5 shows the trend of average citation per document in different collaboration types described earlier. The average citation per document in each of different collaboration types has trended downward over the past 18 years in general, with the exclusion of the past few years. The average citation for papers with different publication years reduced from 48.01 in 1998 to 1.04 in 2015. This proves that citation time window has a notable influence on the average citation per document in COPD. In terms of different collaboration types, international collaboration papers have the highest average citation per document, followed by DMIC papers, and the lowest are SA papers.

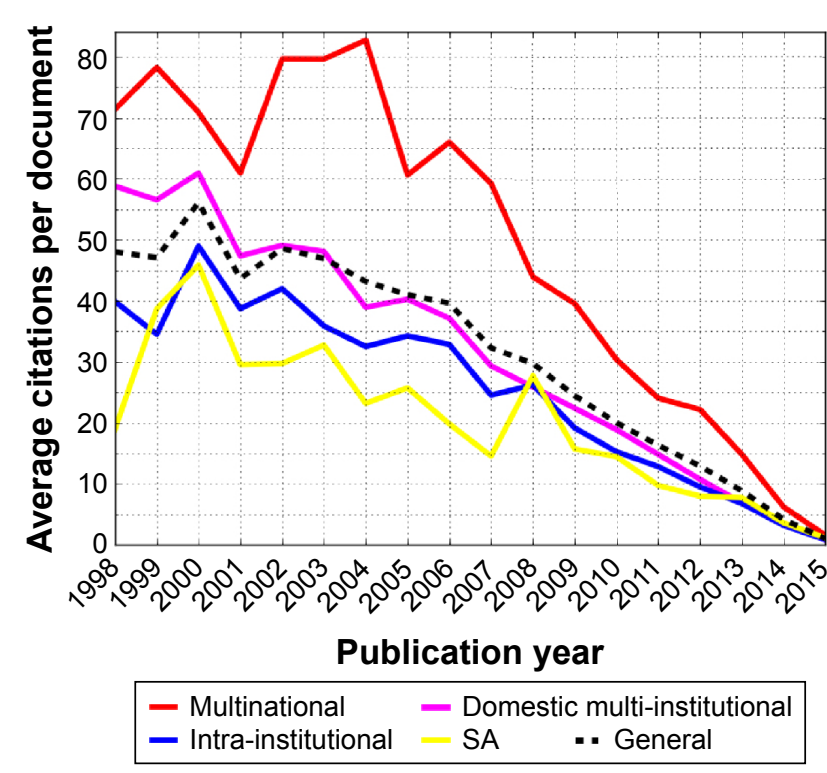

Figure 5 The average citation per document in different collaboration types in COPD publications, 1998-2015.

Abbreviation: SA, single authored. 
Table I The values and ranks (in parenthesis) for 14 institutions that were top ten institutions in the COPD dataset based on at least one of three measures of centrality: degree centrality, betweenness centrality and closeness centrality

\begin{tabular}{|c|c|c|c|c|}
\hline Institution & Degree centrality & Betweenness centrality & Closeness centrality & Country \\
\hline Harvard University & $\mathrm{I}, 274(\mathrm{I})$ & $0.0492(I)$ & $0.4387(\mathrm{I})$ & USA \\
\hline Imperial College London & $\mathrm{I}, 172(2)$ & $0.0442(2)$ & $0.4357(2)$ & UK \\
\hline University of Groningen & $820(4)$ & $0.0211(6)$ & $0.4199(3)$ & The Netherlands \\
\hline INSERM & $801(5)$ & $0.0226(5)$ & $0.4147(4)$ & France \\
\hline University of Edinburgh & $721(8)$ & $0.0090(38)$ & $0.4138(5)$ & UK \\
\hline University of Oxford & $702(9)$ & $0.0101(34)$ & $0.4123(6)$ & UK \\
\hline University of Barcelona & $837(3)$ & $0.0238(4)$ & $0.4114(7)$ & Spain \\
\hline University of British Columbia & $792(6)$ & $0.0239(3)$ & $0.4105(8)$ & Canada \\
\hline Washington University & $767(7)$ & $0.0174(9)$ & $0.4090(9)$ & USA \\
\hline University of Liverpool & $643(\mathrm{II})$ & $0.0087(39)$ & $0.4079(10)$ & UK \\
\hline Toronto University & $593(21)$ & $0.0188(7)$ & $0.3955(33)$ & Canada \\
\hline Hospital Clinic Barcelona & $599(16)$ & $0.0179(8)$ & $0.3903(47)$ & Spain \\
\hline University of Milan & $54 \mid(27)$ & $0.0171(10)$ & $0.3891(49)$ & Italy \\
\hline Brigham and Women's Hospital & $656(10)$ & $0.0116(21)$ & $0.4058(12)$ & USA \\
\hline
\end{tabular}

Note: The institutions are not listed in any particular order.

Abbreviation: INSERM, French National Institute of Health and Medical Research.

\section{Collaborations among research institutions}

\section{Institutions' collaboration network}

Our dataset includes 16,239 institutions, 93.93\% of which $(15,253)$ are involved in the research collaboration activities. They form a network produced by inter-institutional collaboration with an average degree of 17.7 and a density of 0.0011 . There are 351 connected components within the network, with the biggest one including 14,383 institutions (94.3\%). The relationship with the highest value is 256 and exists between Harvard University and Brigham and Women's Hospital. They have the closest research partnership in global COPD research.

Table 1 lists 14 institutions that were top ten institutions in the COPD dataset based on at least one of three measures of centrality: degree centrality, betweenness centrality and closeness centrality. We can see that Harvard University, Imperial College London, University of Groningen, French National Institute of Health and Medical Research (INSERM), University of Barcelona, University of British Columbia and Washington University are the ten most central institutions ranked by degree centrality, betweenness centrality or closeness centrality in the network of collaboration. They are local in the core of the network of collaboration and play a critical role by advocating cooperation within research and ideological exchange on global COPD research. According to the measure of degree centrality, the most prominent institutions are Harvard University and Imperial College London, which have been cooperating with a total of 1,274 and 1,172 different institutions, respectively, from 1998 to 2015.
We used social network analysis software VOSviewer to extract 369 of the most prolific institutions' (production $\geq 50$ ) subnetwork of their collaboration in the COPD research from the original network (Figure 6). The scale of a node represents the number of articles produced by each institution, and the color of a node indicates which cluster the node belongs to. As Figure 6 shows, Harvard University and Imperial College London are located in the core of the visualized network. In all, 13 different scale clusters are detected among most prolific institutions' research collaboration subnetwork by cluster analysis. ${ }^{16}$ Harvard University is the representative of the largest cluster, which contains 93 institutions ( $95 \%$ come from the USA). The next cluster is represented by Imperial College London. This cluster consists of 68 institutions, 51\% of which come from UK, while Denmark and Sweden each account for $15 \%$ of the cluster and the others come from others countries (regions). The third cluster is represented

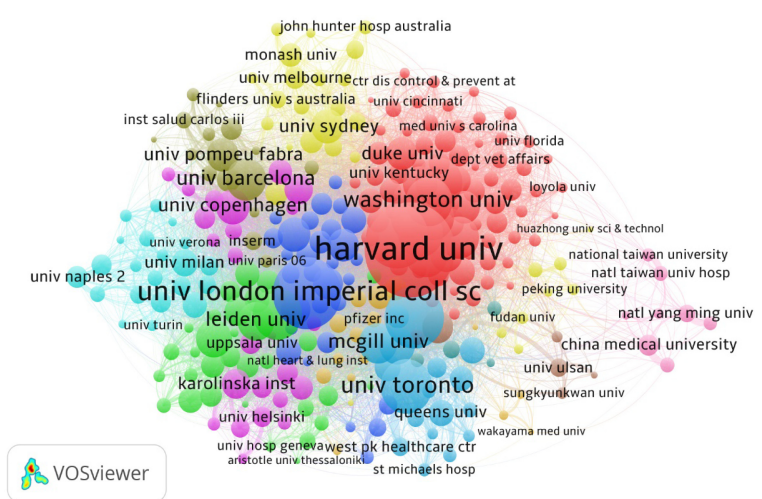

Figure 6 Cluster form in the most 369 prolific institutions' research collaboration network (production $\geq 50$ ). 
by Leiden University, and it consists of 47 institutions, $40 \%$ of which come from the Netherlands, 20\% come from Germany and the others come from other countries (regions). The rest of clusters contain relatively small-scale institutions, and most of institutions in each cluster come from the same country (region). This proves that each entity has a tendency to collaborate with other entities that are located in the same concentrated area or neighboring countries (regions).

\section{Academic impact and scientific collaboration of institutions}

We calculated the academic impact indicator for each of the institutions involved in COPD research. Table 2 represents
35 most prolific institutions (production $\geq 200$ ). Among the 35 most prolific institutions, 15 of the institutions were from the USA, six from UK and five from Canada. Because of this, the countries that had the high-yield institutions were from European or American countries. The only institutions that were not from these regions were Seoul National University and University of Sydney, which are located in South Korea and Australia. The institutions that produced the highest amount of papers were Harvard University, Imperial College London and University of British Columbia, which also happened to be the top three institutions with the highest total citation. The average citation per document of these three institutions was $>40$, and each of their MNCR indicators

Table 2 The academic impact and scientific collaboration indicators of 35 most prolific institutions (production $\geq 200$ )

\begin{tabular}{|c|c|c|c|c|c|c|c|c|c|}
\hline \multirow[t]{2}{*}{ Rank } & \multirow[t]{2}{*}{ Institution } & \multirow[t]{2}{*}{ TP } & \multirow[t]{2}{*}{ TC } & \multirow[t]{2}{*}{ ACPP } & \multicolumn{2}{|l|}{ MNC } & \multicolumn{2}{|l|}{ DMIC } & \multirow[t]{2}{*}{ Country } \\
\hline & & & & & Papers & MNCR (\%) & Papers & DMICR (\%) & \\
\hline I & Harvard University & 787 & 33,984 & 43.18 & 396 & 50.32 & 327 & 41.55 & USA \\
\hline 2 & Imperial College London & 733 & 32,443 & 44.26 & 386 & 52.66 & 173 & 23.6 & UK \\
\hline 3 & University of British Columbia & 527 & 24,433 & 46.36 & 303 & 57.5 & 132 & 25.05 & Canada \\
\hline 4 & Washington University & 450 & 19,987 & 44.42 & 100 & 22.22 & 264 & 58.67 & USA \\
\hline 5 & Johns Hopkins University & 359 & 17,332 & 48.28 & 129 & 35.93 & 170 & 47.35 & USA \\
\hline 6 & University of California, San Francisco & 307 & 16,258 & 52.96 & 101 & 32.9 & 142 & 46.25 & USA \\
\hline 7 & Brigham and Women's Hospital & 418 & 15,710 & 37.58 & 215 & 51.44 & 189 & 45.22 & USA \\
\hline 8 & University of Pittsburgh & 352 & 14,495 & 41.18 & 119 & 33.81 & 166 & 47.16 & USA \\
\hline 9 & University of Edinburgh & 238 & 14,473 & 60.81 & 159 & 66.81 & 33 & 13.87 & UK \\
\hline 10 & University of California, Los Angeles & 336 & 13,404 & 39.89 & $|3|$ & 38.99 & 152 & 45.24 & USA \\
\hline II & University of Toronto & 431 & 13,237 & 30.71 & $|8|$ & 42 & 210 & 48.72 & Canada \\
\hline 12 & Mayo Clinic & 240 & 13,165 & 54.85 & 65 & 27.08 & 87 & 36.25 & USA \\
\hline 13 & McGill University & 345 & 12,509 & 36.26 & I7I & 49.57 & 105 & 30.43 & Canada \\
\hline 14 & University of Barcelona & 341 & 12,453 & 36.52 & 152 & 44.57 & 139 & 40.76 & Spain \\
\hline 15 & Leiden University & 244 & I I,978 & 49.09 & 144 & 59.02 & 76 & 31.15 & The Netherlands \\
\hline 16 & University of Michigan & 312 & 11,049 & 35.41 & 85 & 27.24 & 160 & 51.28 & USA \\
\hline 17 & University of Groningen & 453 & 10,928 & 24.12 & 229 & 50.55 & 125 & 27.59 & The Netherlands \\
\hline 18 & University of Colorado & 338 & 10,898 & 32.24 & 79 & 23.37 & 218 & 64.5 & USA \\
\hline 19 & McMaster University & 261 & 10,680 & 40.92 & 138 & 52.87 & 98 & 37.55 & Canada \\
\hline 20 & University of Copenhagen & 228 & 9,909 & 43.46 & 116 & 50.88 & 82 & 35.96 & Denmark \\
\hline 21 & University of Pennsylvania & 200 & 9,600 & 48 & 54 & 27 & 105 & 52.5 & USA \\
\hline 22 & Duke University & 242 & 8,970 & 37.07 & 81 & 33.47 & 121 & 50 & USA \\
\hline 23 & King's College London & 233 & 8,713 & 37.39 & 130 & 55.79 & 64 & 27.47 & UK \\
\hline 24 & Seoul National University & 229 & 8,454 & 36.92 & 112 & 48.91 & 96 & 41.92 & South Korea \\
\hline 25 & Laval University & 201 & 8,050 & 40.05 & 82 & 40.8 & 70 & 34.83 & Canada \\
\hline 26 & Columbia University & 213 & 7,823 & 36.73 & 80 & 37.56 & 102 & 47.89 & USA \\
\hline 27 & Maastricht University & 299 & 7,753 & 25.93 & 115 & 38.46 & $|3|$ & 43.81 & The Netherlands \\
\hline 28 & University of Manchester & 266 & 7,521 & 28.27 & 145 & 54.51 & 82 & 30.83 & UK \\
\hline 29 & Fondazione Salvatore Maugeri & 212 & 7,192 & 33.92 & 89 & 41.98 & 109 & 51.42 & Italy \\
\hline 30 & University of Birmingham & 217 & 7,172 & 33.05 & 82 & 37.79 & 72 & 33.18 & UK \\
\hline 31 & University of Sydney & 214 & 6,674 & 31.19 & 100 & 46.73 & 98 & 45.79 & Australia \\
\hline 32 & University of North Carolina & 238 & 5,374 & 22.58 & 76 & 31.93 & 123 & 51.68 & USA \\
\hline 33 & University of Milan & 216 & 5,166 & 23.92 & 76 & 35.19 & 108 & 50 & Italy \\
\hline 34 & GlaxoSmithKline & 234 & 4,550 & 19.44 & 155 & 66.24 & 65 & 27.78 & UK \\
\hline 35 & National Jewish Health & 206 & 3,591 & 17.43 & 75 & 36.41 & 113 & 54.85 & USA \\
\hline
\end{tabular}

Note: The institutions ranked by TCs.

Abbreviations: TP, total publication; TC, total citation; ACPP, average citation per paper; MNC, multinational collaboration; DMIC, domestic multi-institutional collaboration; MNCR, multinational collaboration rate; DMICR, domestic multi-institutional collaboration rate. 
Table 3 The values and ranks (in parenthesis) for 38 countries (regions) that were top ten countries (regions) in the COPD dataset based on at least one of three measures of centrality: degree centrality, betweenness centrality and closeness centrality

\begin{tabular}{|c|c|c|c|}
\hline Country/region & $\begin{array}{l}\text { Degree } \\
\text { centrality }\end{array}$ & $\begin{array}{l}\text { Betweenness } \\
\text { centrality }\end{array}$ & $\begin{array}{l}\text { Closeness } \\
\text { centrality }\end{array}$ \\
\hline USA & $51(1)$ & $0.0074(\mathrm{I})$ & $I(I)$ \\
\hline UK & $51(1)$ & $0.0074(\mathrm{I})$ & $I(I)$ \\
\hline Canada & $51(1)$ & $0.0074(\mathrm{I})$ & I (I) \\
\hline Australia & $51(1)$ & $0.0074(\mathrm{I})$ & $\mathrm{I}(\mathrm{I})$ \\
\hline Sweden & $50(2)$ & $0.0063(2)$ & $0.9808(2)$ \\
\hline Spain & $50(2)$ & $0.006(3)$ & $0.9808(2)$ \\
\hline Italy & $50(2)$ & $0.006(3)$ & $0.9808(2)$ \\
\hline France & $50(2)$ & $0.006(3)$ & $0.9808(2)$ \\
\hline Germany & $50(2)$ & $0.006(3)$ & $0.9808(2)$ \\
\hline The Netherlands & $50(2)$ & $0.006(3)$ & $0.9808(2)$ \\
\hline Switzerland & $49(3)$ & $0.0057(4)$ & $0.9623(3)$ \\
\hline Norway & $49(3)$ & $0.0049(5)$ & $0.9623(3)$ \\
\hline Japan & $49(3)$ & $0.0048(6)$ & $0.9623(3)$ \\
\hline Austria & $48(4)$ & $0.0051(7)$ & $0.9444(4)$ \\
\hline Argentina & $48(4)$ & $0.0042(8)$ & $0.9444(4)$ \\
\hline South Africa & $48(4)$ & $0.0038(9)$ & $0.9444(4)$ \\
\hline Denmark & $48(4)$ & $0.0036(10)$ & $0.9444(4)$ \\
\hline Belgium & $47(5)$ & $0.004 \mathrm{I}(\mathrm{II})$ & $0.9273(5)$ \\
\hline Greece & $47(5)$ & 0.003 I (I2) & $0.9273(5)$ \\
\hline China Mainland & $47(5)$ & $0.0031(12)$ & $0.9273(5)$ \\
\hline Brazil & $47(5)$ & $0.0031(12)$ & $0.9273(5)$ \\
\hline Russia & $47(5)$ & $0.003(13)$ & $0.9273(5)$ \\
\hline Poland & $46(6)$ & $0.0048(6)$ & $0.9107(6)$ \\
\hline India & $46(6)$ & $0.0047(14)$ & $0.9107(6)$ \\
\hline Turkey & $46(6)$ & $0.004(15)$ & $0.9107(6)$ \\
\hline Ireland & $46(6)$ & $0.002(16)$ & $0.9107(6)$ \\
\hline South Korea & $45(7)$ & $0.0033(17)$ & $0.8947(7)$ \\
\hline Iran & $45(7)$ & $0.0016(18)$ & $0.8947(7)$ \\
\hline Venezuela & $43(8)$ & $0.0027(19)$ & $0.8644(8)$ \\
\hline New Zealand & $43(8)$ & $0.0019(20)$ & $0.8644(8)$ \\
\hline Finland & $43(8)$ & $0.0016(18)$ & $0.8644(8)$ \\
\hline Hungary & $42(9)$ & 0.0031 (I2) & $0.85(9)$ \\
\hline Israel & $42(9)$ & $0.0025(21)$ & $0.85(9)$ \\
\hline Mexico & $42(9)$ & $0.0013(22)$ & $0.85(9)$ \\
\hline Croatia & $41(10)$ & $0.0015(23)$ & $0.8361(10)$ \\
\hline North Ireland & $41(10)$ & 0.0009 (24) & $0.8361(10)$ \\
\hline Chile & $41(10)$ & $0.0008(25)$ & $0.8361(10)$ \\
\hline Portugal & $41(10)$ & $0.0006(26)$ & $0.8361(10)$ \\
\hline
\end{tabular}

Note: The countries (regions) are not listed in any particular order.

surpass the DMICR. As mentioned earlier, we can conclude that these outstanding institutions not only take the leading role in the development of their own countries or regions but also play an important role in international research cooperation in COPD.

\section{Collaborations among countries (regions) Countries' (regions') collaboration network}

Our dataset involved 140 countries (regions). We excluded 88 countries (regions) whose paper production had been $<50$ in the past 18 years. Using the rest of 52 countries, we constructed a collaboration network, depicting the relationships between these countries (regions). In this network, the density was 0.84 and the average degree was 42.8 , which obviously indicated that there are strong relationships among 52 countries (regions) in the field of COPD. The highest line value (897) existed between the USA and UK, which indicated that the USA and UK have had 897 joint publications during 1998-2015. The average degree of the 52 countries (regions) was 42.8 , which means that each country (region) has $\sim 43$ partners in the collaboration network.

Table 3 lists 38 countries (regions), which were top ten countries (regions), in the COPD dataset based on at least one of three measures of centrality: degree centrality, betweenness centrality and closeness centrality. We can see that the USA, UK, Canada and Australia are the most central countries (regions) ranked by degree centrality, betweenness centrality or closeness centrality in the collaboration network. Therefore, we can conclude that the four countries are very active in scientific research activities in the field of COPD.

Figure 7 is a visual representing the collaboration network between the different countries (regions). The size of the node represents the amount of papers produced in that region, and the color of node shows which cluster each region is located in the collaboration network. The thickness of the links connecting the nodes represents the strength or number of collaborations between the countries (regions) it connects. We can find that western countries (regions) cooperate together closely and are located at the core positions, while eastern countries

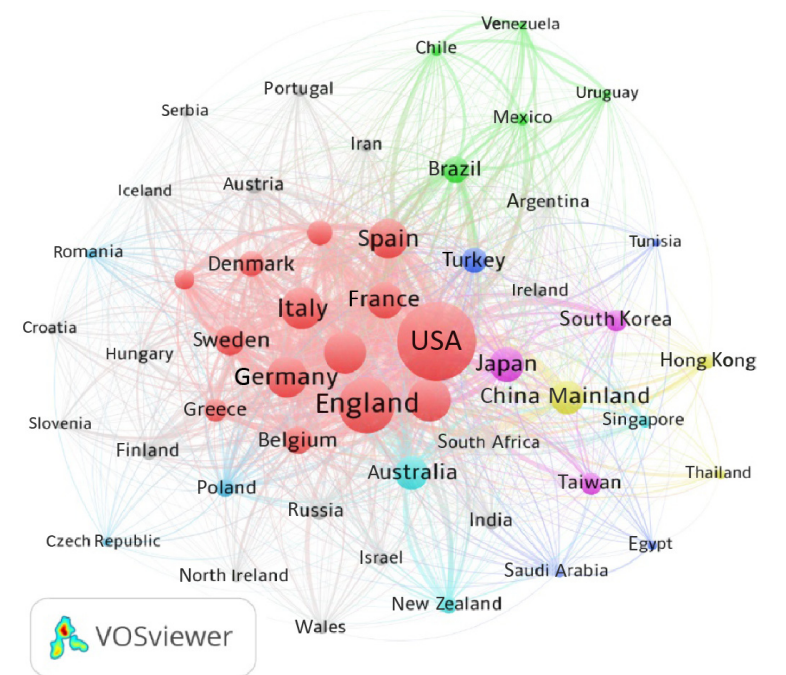

Figure 7 Collaboration network visualization of countries (regions) in COPD (production $\geq 50$ ). 
(regions) such as Japan, China Mainland, Taiwan, Korea and India remain scattered on the periphery of the network.

\section{Academic impact and scientific collaboration of countries (regions)}

While there is no difference between the centrality indicators of the USA, UK, Canada and Australia, Table 4 shows that the USA has the highest values in the amount of papers produced and the TC in the COPD study. The paper production of the USA is 2.2 times that of the second, which is UK, and its TC is 1.9 times greater than that of the UK. In terms of average citation, the most prominent country (region) is Denmark with the average citation 39.17. The reason, however, why Denmark does not have a high amount of TC is because it only ranked 17th in the amount of research papers produced. Hence, the indicator of average citation is not suitable to be used alone to evaluate the academic impact of a country (region). The USA has not only produced the highest amount of papers but also ranks highly in ACPP at 31.06. Note that, the other countries (regions) with lower multi-internal collaboration rate score $(<30 \%)$ mainly come from Asia, including China Mainland, South Korea, Japan and Taiwan. The country with the highest share of multinationally produced publications is Switzerland, at $67.69 \%$. Although the USA produces a low percentage of multinational publications compared to its overall output, it is a major producer of international publications because it produces the largest total number of publications.

\section{Research collaboration field in COPD}

In August 2011, Thomson Reuters launched version 5 of the Science and Social Science Citation Index in the Web of Science. The journals indexed in SCI and SSCI were divided into $225 \mathrm{Web}$ of Science categories. ${ }^{17}$ Parts of the journals may belong to multi-discipline categories. In order to improve the understanding of the change in collaboration within different fields, we analyzed the change in subject categories in COPD study.

As a whole, the amount of subject categories refers to the COPD research that has witnessed an increasing trend from 78 in 1998 to 128 in 2015. In terms of different collaboration types, the subject categories involved in DMIC and multinational have increased from 52 and 32 in 1998 to 106 and 90 in 2015, respectively. The results show that the study of COPD attracts a growing number of scholars' interest from different disciplines.

Figures 8 and 9 represent the changes in the percentage of top ten active subject categories in DMIC and international collaboration papers in COPD. By comparing the major discipline categories in different collaboration types in COPD, we find that both DMIC and international collaboration are mainly concentrated in seven discipline categories, including respiratory system, general and internal medicine,

Table 4 The academic impact and scientific collaboration indicators of 20 most prolific countries (regions)

\begin{tabular}{|c|c|c|c|c|c|c|c|}
\hline \multirow[t]{2}{*}{ Rank } & \multirow[t]{2}{*}{ Country/region } & \multirow[t]{2}{*}{$\mathbf{T P}$} & \multirow[t]{2}{*}{ TC } & \multirow[t]{2}{*}{ ACPP } & \multicolumn{2}{|l|}{ MNC } & \multirow[t]{2}{*}{ Income group } \\
\hline & & & & & Papers & MNCR (\%) & \\
\hline I & USA & 9,679 & 300,621 & 31.06 & 3,136 & 32.4 & High income \\
\hline 2 & UK & 4,419 & $|60,08|$ & 36.23 & 2,219 & 50.21 & High income \\
\hline 3 & Canada & 2,321 & 82,949 & 35.74 & $\mathrm{I}, 15 \mathrm{I}$ & 49.59 & High income \\
\hline 4 & The Netherlands & 2,235 & 70,021 & 31.33 & $\mathrm{I}, 057$ & 47.29 & High income \\
\hline 5 & Italy & 2,309 & 62,467 & 27.05 & 887 & 38.41 & High income \\
\hline 6 & Spain & 1,979 & 57,703 & 29.16 & 696 & 35.17 & High income \\
\hline 7 & Germany & 2,150 & 46,766 & 21.75 & 1,035 & 48.14 & High income \\
\hline 8 & Australia & 1,332 & 36,821 & 27.64 & 519 & 38.96 & High income \\
\hline 9 & France & $\mathrm{I}, 564$ & 35,987 & 23.01 & 608 & 38.87 & High income \\
\hline 10 & Japan & $\mathrm{I}, 502$ & 31,962 & 21.28 & 332 & 22.1 & High income \\
\hline II & Belgium & 844 & 27,344 & 32.4 & 507 & 60.07 & High income \\
\hline 12 & Sweden & $\mathrm{I}, 002$ & 27,327 & 27.27 & 539 & 53.79 & High income \\
\hline 13 & Denmark & 660 & 25,854 & 39.17 & 351 & 53.18 & High income \\
\hline 14 & Switzerland & 715 & 20,327 & 28.43 & 484 & 67.69 & High income \\
\hline 15 & China Mainland & $\mathrm{I}, 372$ & 14,684 & 10.7 & 405 & 29.52 & Upper middle income \\
\hline 16 & Brazil & 766 & 12,406 & 16.2 & 238 & 31.07 & Upper middle income \\
\hline 17 & Greece & 523 & 10,058 & 19.23 & 216 & 41.3 & High income \\
\hline 18 & Turkey & 708 & 6,329 & 8.94 & 65 & 9.18 & Upper middle income \\
\hline 19 & Taiwan & 471 & 5,339 & 11.34 & 80 & 16.99 & High income \\
\hline 20 & South Korea & 509 & 4,326 & 8.5 & 125 & 24.56 & High income \\
\hline
\end{tabular}

Notes: The countries (regions) are ranked by TC. Income group was sourced from https://datahelpdesk.worldbank.org/knowledgebase/articles/9065/9. ${ }^{22}$

Abbreviations: TP, total publication; TC, total citation; ACPP, average citation per paper; MNC, multinational collaboration; MNCR, multinational collaboration rate. 


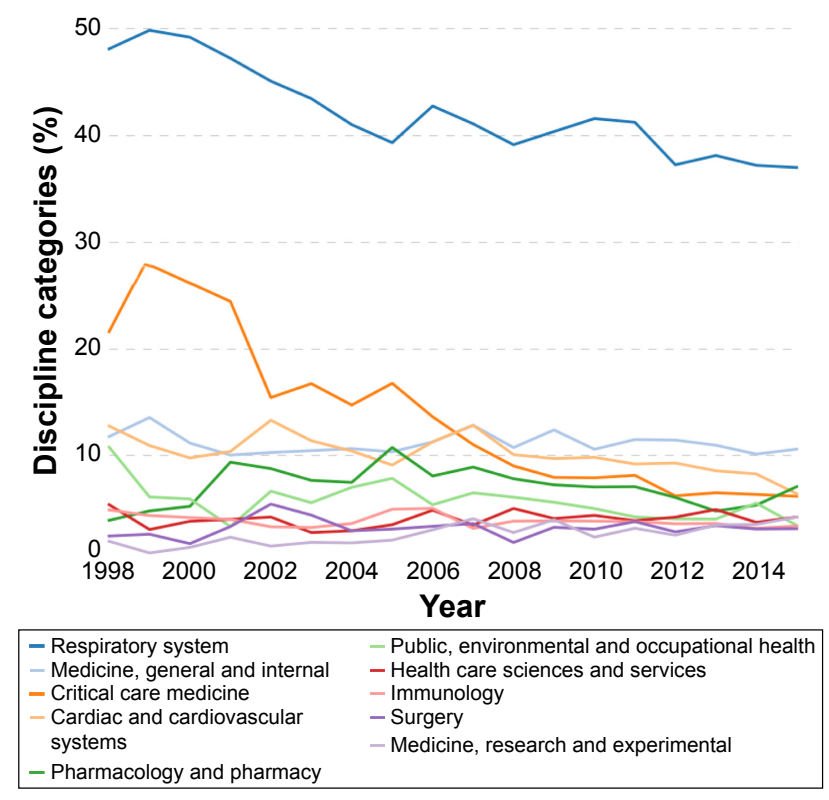

Figure 8 Changes in top ten fields of DMIC in COPD.

Note: The legend ranked by total frequency in DMIC during 1998-2015.

Abbreviation: DMIC, domestic multi-institutional collaboration.

critical care medicine, cardiac and cardiovascular systems, pharmacology and pharmacy, public, environmental and occupational health and immunology.

\section{Discussion and conclusion \\ Research cooperation becoming increasingly frequent}

The number of publications in the COPD field has been growing, especially after 2004. Coauthorship on publications has

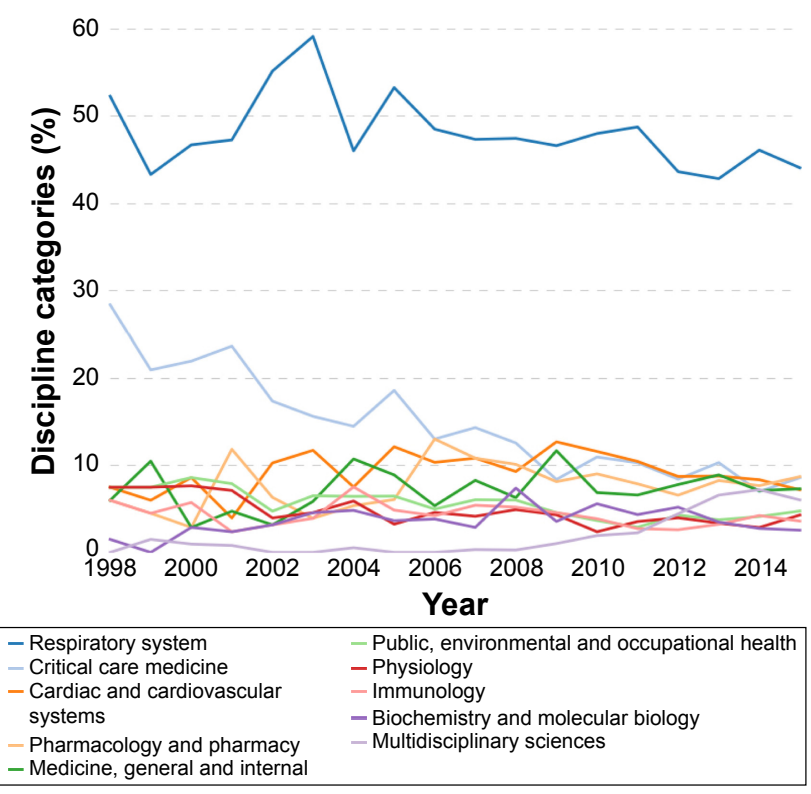

Figure 9 Changes in top ten fields of MNC in COPD.

Note: The legend ranked by total frequency in MNC during 1998-20I5

Abbreviation: MNC, multinational collaboration. also been growing. The trend is the same as in the previous study $^{18,19}$ in other fields. Overall, the COPD research can be classified as an area of research that has a high amount of author collaboration, with $95 \%$ of its publications having been produced by more than one author all over the world during the past 18 years. In terms of different collaborations, the percentages of papers produced through MNC, DMIC and IIC are $21 \%, 43 \%$ and $31 \%$, respectively. Our data indicate that scientists value research produced with others. Therefore, we can conclude that researchers have a great tendency to collaborate in the field of COPD.

\section{Good performance and bright future in global COPD study}

The analytic results showed that papers produced in each of the different collaboration types have resulted in different citation frequencies. The MNC papers have the highest academic impact, followed by the DMIC papers and the lowest are SA papers. Trend analysis of the percentage of different collaboration types shows us that the percentages of DMIC papers and MNC papers have been increasing constantly from 1998 to 2015, while the percentages of IIC papers and SA papers in COPD research show the opposite tendency. Because a majority of the research in the field of COPD has been produced through cross-national collaboration and DMIC, it means that the papers in this field will be developed into a higher quality.

The trends analysis of the average number of entities per paper shows that the average number of authors, institutions and countries (regions) in COPD has increased. On the one hand, researchers benefit from intellectual exchanges with foreign colleagues and reduced costs by sharing technologies and resources with others, ${ }^{20}$ on the other hand, with the in-depth research, it will be even more difficult to obtain a major breakthrough only by a single researcher or institution, and this forces researchers in COPD to cooperate with others.

\section{Prominent institutions are found in COPD field}

According to the centrality analysis, the most active institutions in COPD cooperation research are Harvard University, Imperial College of Science Technology and Medicine, University of Groningen, INSERM, University of Barcelona, University of British Columbia and Washington University. They play a critical role in cooperating with different institutions and are involved in ideological exchange in global COPD research. Applying the method of clustering, we found 13 clusters in institutions' collaboration network. 
Most of institutions in the same cluster come from the same or neighboring countries (regions). It means that geographic distance can be the major limiting factor in COPD cooperation research. Highly ranked institutions in academic impact and scientific collaboration indicators also include Harvard University, Imperial College London and University of Groningen. The most prolific 35 institutions' research output was $\geq 200$. A large portion of these publications are produced through DMIC and MNC. These institutions not only take the leading role in the development of their own countries (regions) but also play a critical role in international research cooperation in COPD.

\section{Collaboration and performance of countries (regions) in COPD shared a close relationship with economic level}

According to the analysis of the cooperation network, 52 countries (regions) have frequently collaborated in COPD study. Cooperating among countries (regions), the USA, UK, Canada and Australia are in the center of the network and play a leading role in information dissemination and control of resources in COPD. However, when it comes to research paper production and TC, the USA has absolute advantages in COPD study. As reported by the WHO, "almost $90 \%$ of COPD deaths occur in low- and middle-income countries". However, the study found both paper production and the close degree of cooperation are concentrated in high-income countries (regions) and some of upper middle-income countries (regions). This is same as in the previous study ${ }^{21}$ about COPD. These facts pose a challenge to the researchers and policymakers on how to achieve the goal of reducing the global burden of COPD through cooperation of research between different countries (regions).

\section{Increasingly extensive collaboration in various fields in COPD}

Both DMIC and MNC are mainly concentrated in respiratory system and critical care medicine. Looking at the overall trends, we see that the percentage of papers with regard to these two major disciplines has been reduced, especially the percentage of critical care medicine, from $28 \%$ in DMIC and MNC in 1998 to $9 \%$ and 6\% in 2015, respectively. In addition, the major other five disciplines, including general and internal medicine, cardiac and cardiovascular systems, pharmacology and pharmacy, public environmental and occupational health and immunology, in DMIC and MNC range from $0 \%$ to $15 \%$. The highest percentage of the disciplines has been constantly decreasing, while the percentage of other top ten disciplines has remained at a stable level. From the study, we deduced that there will be increasingly extensive disciplines involved with COPD. Both DMIC and MNC papers show that an increasing attention has been aroused toward the research on COPD from more and more different academic domains.

In conclusion, by scientometric methods and social network analysis, this study provides a global description of multiple collaboration types in COPD research. International and intranational collaborations should be encouraged in this field. Low- and middle-income countries (regions) ought to strengthen collaboration with upper-income countries (regions) in COPD research. In addition, these results and proposal would provide an important reference for scholars in this field as well as policymakers and managers for managing and funding COPD research in the future.

\section{Study limitations}

This paper focuses upon research papers as a measurement of the academic collaboration between different institutions and countries (regions). However, there is much more to consider in academic collaboration. Something to consider for the future is the value of collaboration in patents or monographs. How do these compare in terms of academic impact versus that of a research paper, and how can this be quantified to be directly compared? These are questions that need to be investigated in future studies.

\section{Acknowledgments}

This work was funded by the National Natural Science Foundation of China (Grant No 71473154). The authors would like to thank the reviewers of this article for their many valuable suggestions and thoughtful comments.

\section{Disclosure}

The authors report no conflicts of interest in this work.

\section{References}

1. World Health Organization. World Health Statistics Report-2008. Geneva, Switzerland: World Health Organization Press; 2008.

2. Domenech A, Puig C, Martí S, et al. Infectious etiology of acute exacerbations in severe COPD patients. J Infect. 2013;67(6):516-523.

3. Ko FWS, Ip M, Chan PKS, et al. Viral etiology of acute exacerbations of COPD in Hong Kong. Chest. 2007;132(3):900-908.

4. Barnestein-Fonseca P, Leiva-Fernández J, Vidal-España F, García-Ruiz A, Prados-Torres D, Leiva-Fernández F. Is it possible to diagnose the therapeutic adherence of patients with COPD in clinical practice? A cohort study. BMC Pulm Med. 2010;11(11):6.

5. Celli BR, Macnee W. Standards for the diagnosis and treatment of patients with COPD: a summary of the ATS/ERS position paper. Eur Respir J. 2004;23(6):932-946. 
6. Casas HA, Casas Herrera A, Montes de Oca M, et al; PUMA Team. COPD underdiagnosis and misdiagnosis in a high-risk primary care population in four Latin American countries. A key to enhance disease diagnosis: the PUMA study. PLoS One. 2016;11(4):e0152266.

7. Tinkler ML. Using lung cancer screening as an opportunity to diagnose COPD [J]. Thorax. 2012;67(7):662-662.

8. Giembycz MA, Field SK. Roflumilast: first phosphodiesterase 4 inhibitor approved for treatment of COPD. Drug Des Devel Ther. 2010;4(14):147-158.

9. Miravitlles M, Soler-Cataluña JJ, Calle M, et al; Spanish Society of Pulmonology and Thoracic Surgery. Spanish COPD guidelines (GesEPOC): pharmacological treatment of stable COPD. Arch Bronconeumol. 2012;48(7):247-257.

10. Donohue JF, Singh D, Kornmann O, Lawrence D, Lassen C, Kramer B. Safety of indacaterol in the treatment of patients with COPD. Int $J$ Chron Obstruct Pulmon Dis. 2011;6(1):477-492.

11. Albert RK, Connett J, Bailey WC, et al. Azithromycin for prevention of exacerbations of COPD. N Engl J Med. 2011;365(8):689-698.

12. Vogelmeier C, Hederer B, Glaab T, et al. Tiotropium versus salmeterol for the prevention of exacerbations of COPD. N Engl J Med. 2011; 364(12):1093-1103.

13. Aaron SD. Management and prevention of exacerbations of COPD. BMJ. 2014;349:g5237.

14. Han P, Shi J, Li X, Wang D, Shen S, Su X. International collaboration in LIS: global trends and networks at the country and institution level. Scientometrics. 2014;98(1):53-72.
15. Márcia O, João G. An overview of social network analysis. Wiley Interdiscip Rev Data Min Knowl Discov. 2012;2(2):99-115.

16. Waltman L, Eck NJV, Noyons ECM. A unified approach to mapping and clustering of bibliometric networks. J Inform. 2010;4(4): 629-635.

17. Zhao Y, Li D, Han M, Li C, Li D. Characteristics of research collaboration in biotechnology in China: evidence from publications indexed in the SCIE. Scientometrics. 2016;107(3):1373-1387.

18. Yu Q, Shao H, He P, Duan Z. World scientific collaboration in coronary heart disease research. Int J Cardiol. 2012;167(3):631-639.

19. Zhang C, Qi Y, Fan Q, Duan Z. Research collaboration in health management research communities. BMC Med Inform Decis Mak. 2013; 13(1):1-13.

20. Chang HW, Huang MH. Prominent institutions in international collaboration network in astronomy and astrophysics. Scientometrics. 2013;97(2):443-460.

21. Gu W, Yuan Y, Hua Y, Qi G, Jin X, Jin Y. A bibliometric analysis of the 100 most influential papers on COPD. Int J Chron Obstruct Pulmon Dis. 2015;10(Issue 1):667-676.

22. World Bank Country and Lending Groups [Updated 2016]; 2016. Available from: https://datahelpdesk.worldbank.org/knowledgebase/ articles/906519. Accessed August 5, 2016.
International Journal of COPD

\section{Publish your work in this journal}

The International Journal of COPD is an international, peer-reviewed journal of therapeutics and pharmacology focusing on concise rapid reporting of clinical studies and reviews in COPD. Special focus is given to the pathophysiological processes underlying the disease, intervention programs, patient focused education, and self management protocols.

\section{Dovepress}

This journal is indexed on PubMed Central, MedLine and CAS. The manuscript management system is completely online and includes a very quick and fair peer-review system, which is all easy to use. Visit http://www.dovepress.com/testimonials.php to read real quotes from published authors. 